\title{
Lúpus Neonatal e Lúpus Eritematoso Cutâneo Subagudo na Infância ${ }^{(*)}$
}

\section{Neonatal Lupus and Cutaneous Subacute Lupus Erythematosus In Childhood}

\author{
Marlene Freire ${ }^{(1)}$, Reginaldo Botelho Teodoro( ${ }^{(2)}$, José Humberto da Silva ${ }^{(3)}$, Alfredo Leboreiro Fernandez ${ }^{(4)}$, \\ Lília Beatriz Oliveira ${ }^{(5)}$ e José Antônio de Paula Bianco ${ }^{(6)}$
}

\section{RESUMO}

O lúpus eritematoso (LE) raramente ocorre na infância e, quando aparece, manifesta-se, mais freqüentemente, sob a forma de lúpus eritematoso sistêmico. A forma restrita à pele é extremamente incomum e pode apresentar-se nas variantes lúpus eritematoso discóide, lúpus eritematoso cutâneo subagudo (LECS) e lúpus neonatal (LN). Em razão dessa raridade e com vistas aos dados reportados na literatura, apresentamos dois casos de lúpus cutâneo em crianças. O caso um refere-se a um paciente masculino, branco, cinco anos, com lesões de pele eritematoso-descamativas, alopecia, artralgia e dificuldade para deambular. O exame neurológico evidenciou paraparesia espástica com sinais de liberação piramidal. O caso dois refere-se a um lactente de um mês, masculino, filho de mãe com LECS, com lesões de pele eritematoso-ovalares presentes ao nascimento, além de anemia, plaquetopenia e evidência ecocardiográfica de canal arterial pérvio. O diagnóstico de LN foi baseado nos dados clínicos, laboratoriais, histopatológico e antecedentes familiares. Concluímos com a apresentação desses casos que, em razão da raridade do lúpus cutâneo na infância, diante de casos suspeitos, deve-se estar atento para o diagnóstico precoce e acompanhamento dos pacientes, de modo a prevenir possíveis complicações e sistematização da doença.

Palavras-chave: lúpus eritematoso sistêmico (LES), lúpus neonatal (LN), lúpus eritematoso cutâneo subagudo (LECS), colagenose.

\begin{abstract}
Although Lupus Erythematosus (LE) rarely occurs in childhood when it does the most frequent form is the systemic one (SLE). Lupus Erythematosus restricted to the skin is particularly rare and can be classified into three variants: chronic discoid LE (CDLE), subacute cutaneous LE (SCLE), and neonatal lupus erythematosus (NLE). Based on literature data and in the rarity of the disease, we present two cases of cutaneous lupus in infants. One case of SCLE started in a four-month child presenting systematization manifested by neurological disorder by the age of 5 years old; and one of LN. This case refers to a white, male, 5 year-old patient, with multiple round lesions with papulo-squamous, alopecia, arthralgias and walking disorder. The neurological exam presented retarded motor development and signs of pyramidal syndrome. In the second case we report neonatal lupus erythematosus in a one-month child, whose mother had SCLE, presenting annular erythematous skin lesions noticed at birth. Other clinical features included anemia, thrombocytopenia and patent ductus arteriosus. The diagnosis of NLE was based on laboratory, histology, and family antecedents clinical data. We considering that the rarity of infant cutaneous lupus, when facing suspicious cases, we should pay close attention in order to established early diagnosis and careful follow-up to detect possible complications and systematization of the disease.
\end{abstract}

Keywords: Systemic Lupus Erythematosus (SLE), neonatal lupus (NLE), cutaneous subacute lupus erythematosus (SCLE), collagen disease.

\footnotetext{
* Disciplina de Reumatologia do departamento de clínica médica da Faculdade de Medicina do Triângulo Mineiro (FMTM) Recebido em 25/09/2003. Recebido em 21/02/2003. Aprovado, após revisão, em 06/01/2004.

1. Professora adjunta da disciplina de Reumatologia da FMTM

2. Médico assistente da disciplina de Reumatologia da FMTM.

3. Professor adjunto da disciplina de Dermatologia da FMTM.

4. Professor adjunto da disciplina de Neurologia da FMTM.

5. Residente (R2) em Reumatologia na FMTM.

6. Residente (R3) em Reumatologia na FMTM.
}

Endereço para correspondência: Marlene Freire. Departamento de clínica médica. Disciplina de Reumatologia da Faculdade de Medicina do Triângulo Mineiro (FMTM). R. Getúlio Guaritá s/n, bairro Abadia, CEP 38025-110, Uberaba, MG. 


\section{INTRODUÇÃO}

O lúpus eritematoso (LE) pode ser dividido em três variantes: lúpus eritematoso sistêmico (LES), lúpus eritematoso discóide crônico (LEDC) e lúpus eritematoso cutâneo subagudo (LECS) $)^{(1)}$.

O LE é raro na infância, e quando ocorre, manifesta-se mais freqüentemente sob a forma de LES. A forma restrita à pele é particularmente rara. O lúpus eritematoso cutâneo subagudo (LECS) é extremamente incomum em crianças, e freqüentemente associado com a deficiência de complemento ${ }^{(2)}$.

O LECS, descrito por Sontheimer et al. em 1979(3), apresenta duas variantes clínicas: o tipo anular e o psoriasiforme ${ }^{(1)}$. Caracteriza-se por achados clínicos típicos e presença do anticorpo anti $\mathrm{Ro}^{(4)}$.

Uma outra variante na infância, o lúpus neonatal (LN), é causada pela passagem de anticorpos anti-Ro da mãe para o feto através da placenta. Os achados clínicos são lesões cutâneas, bloqueio cardíaco congênito, doença hepática colestática e trombocitopenia. Embora não tenha prevalência conhecida, estima-se ocorrer em torno de 1:20.000 recém-nascidos $^{(5)}$. O tegumento é afetado em aproximadamente $50 \%$ dos casos, e as lesões aparecem durante as primeiras semanas de vida. Essas lesões apresentam-se como manchas eritematosas anulares, algumas vezes com descamação leve e fino enrugamento indicativo de atrofia ${ }^{(4,5)}$; elas desaparecem até os seis meses de vida ${ }^{(5)}$.

Baseados em dados de literatura e por serem raros na infância, apresentamos dois casos de lúpus cutâneo em crianças: um caso de lúpus cutâneo subagudo com aparecimento após quatro meses de idade, com sistematização aos cinco anos pelas manifestações neurológicas, e outro, de lúpus neonatal.

\section{RELATO DE CASO 1}

LBB, branco, masculino, cinco anos, encaminhado ao ambulatório de Reumatologia da Faculdade de Medicina do Triângulo Mineiro, com queixas de lesões de pele desde os quatro meses de vida. A mãe referia que, com quatro meses de vida, a criança apresentou lesões de pele arroxeadas nos membros inferiores, superiores e na face. Referia que essas lesões melhoraram com tratamento para alergia, mas recidivaram.

Há oito meses, iniciou com úlceras orais dolorosas que, episodicamente, infectavam e melhoravam com uso de antibióticos. Há três semanas, as lesões orais pioraram, juntamente com as lesões de pele. A criança deixou de se alimentar e iniciou com quadro de fraqueza generalizada, associada à febre duas vezes ao dia e artralgia em ombros.
Referia hábito urinário normal, constipação intestinal, além de lesões na mucosa anal e dor à evacuação. Referia que a criança apresentava dificuldade em deambular. Negava outras queixas e alterações nos diversos aparelhos e sistemas. Referiu, ainda, que ela nasceu de parto normal com peso de 3.390 gramas e 54 centímetros de estatura, cartão de vacinação completo. Bom desenvolvimento psicomotor. Os sintomas neurológicos iniciaram-se aos quatro anos, com dificuldade progressiva da marcha. Ao exame fisico, o paciente estava em estado geral regular, eupnéico, acianótico, afebril, secreção conjuntival purulenta, mucosas descoradas $(++/+4)$, desidratadas $(++/+4)$. Queilite angular e úlceras sangrantes nos lábios com crostas e descamações (Figura 1A). Pressão arterial de 110x60 $\mathrm{mmHg}$, bulhas rítmicas, normofonéticas, sem sopros, a 120 bpm. Aparelho respiratório e abdome sem alterações. Lesões eritêmato-descamativas na pele: algumas purpúricas, no tronco, membros superiores e inferiores, orelhas e couro cabeludo, além de petéquias nas mãos e pés (Figuras 1B e 1C). Apresentava alopecia. Região anal com presença de fissuras, sangramento e descamação. Membros superiores sem alterações. Exame neurológico: sinais de liberação piramidal, dificuldade de marcha e sensibilidade preservada. Exames laboratoriais: hemoglobina de 10,3g/dl; hematócrito de 31,9\%; hemácias 4,07 milhões $/ \mathrm{mm}^{3}$, plaquetas: $239.000 / \mathrm{mm}^{3}$, leucócitos: $6700 / \mathrm{mm}^{3}$ com diferencial de $6 \%$ de bastonetes, $53 \%$ de segmentados, $1 \%$ de eosinófilos, $4 \%$ basófilos, $35 \%$ de linfócitos, $1 \%$ de monócitos; aspartato aminotranferase (AST): 82U/L, alanina aminotransferase (ALT): 45U/L, fosfatase alcalina: $118 \mathrm{U} / \mathrm{L}$; ferro sérico: $27 \mathrm{mcg} / \mathrm{dl}$, ferritina $98 \mathrm{mg} / \mathrm{ml}$ capacidade latente de ligação do ferro $229 \mathrm{mg} / \mathrm{dl}$, capacidade total de ligação do ferro: $255 \mathrm{mg} / \mathrm{dl}$, índice de saturação 10\%; alfa 1 glicoproteína ácida: 1,7g/l, PCR: 0,6mg/dl, VHS: 60mm, C3: 121,2mg/ dl, C4: 48,9mg/dl, fator reumatóide 118,7UI/ml; FAN (Hep 2) -1:640(padrão pontilhado), antiSSA/Ro positivo (1:6.400), antiDNA nativo, antiANCA, antiRNP e antiSSB/ La negativos. Urina I normal, proteinúria de 24 horas ausente. Ressonância nuclear magnética do encéfalo e de medula normais, análise do líquor normal. Biópsia de pele no antebraço direito: epiderme com hiperceratose, focos de atrofia e outros com permeação de linfócitos na camada basal. Espessamento e vacuolização da camada basal. Derme com depósitos de mucina, extravasamento de hemácias, discreto infiltrado de linfócitos, por vezes perianexial superficial. Imunofluorescência direta negativa para IgA e fibrinogênio, depósito discreto de IgG, descontínuo, linear, granular na membrana basal; IgM e C3 com depósito 
intenso, linear, granular na membrana basal (Figura 1D). Baseado nos achados clínicos, laboratoriais e histopatológicos, foi feito o diagnóstico de lúpus eritematoso cutâneo subagudo com sistematização. $O$ tratamento inicial estabelecido consistiu em antibioticoterapia para infecção mucocutânea, com ceftriaxona 1,2g/dia, e medidas de suporte. Após resultados laboratoriais e biópsia, iniciou-se corticoterapia com prednisolona $15 \mathrm{mg} /$ dia e hidroxicloroquina na dose de $4 \mathrm{mg} / \mathrm{kg} /$ dia. Evoluiu, após três meses,
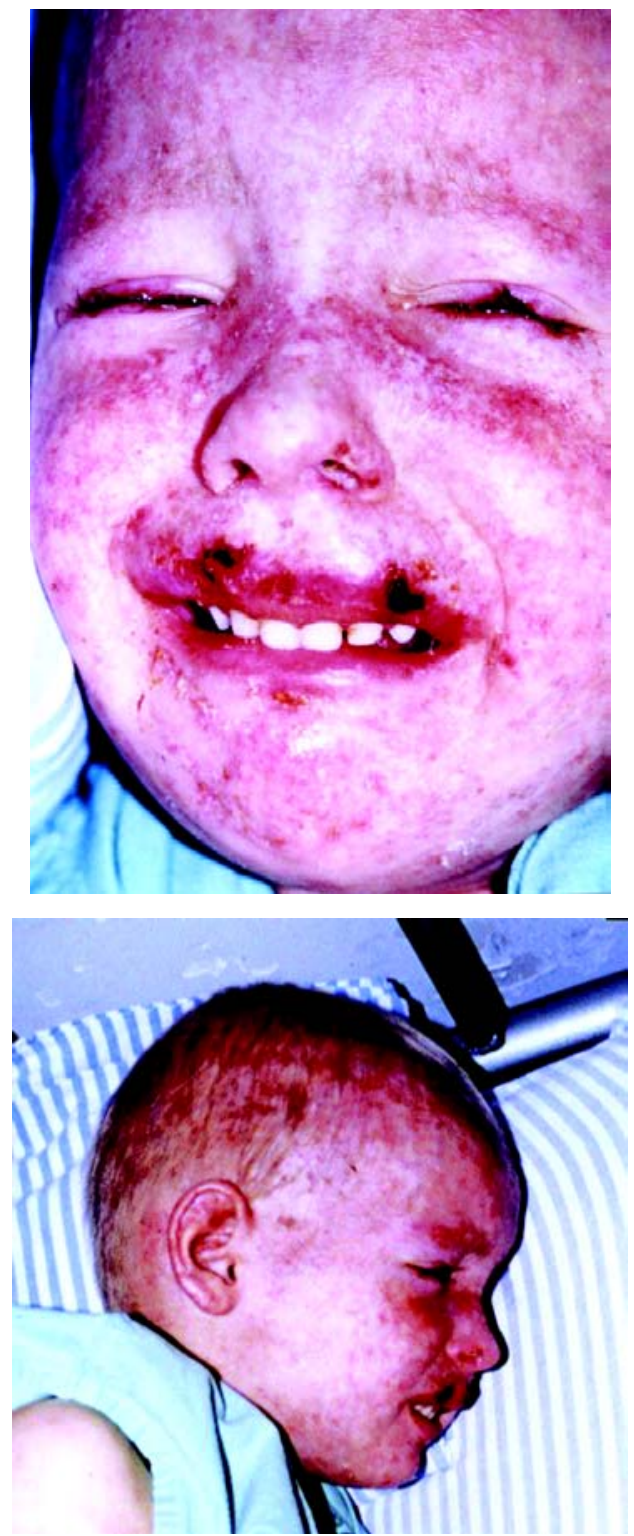

FiguRA $1 \mathrm{~A}$ - Queilite angular e úlceras sangrantes nos lábios com crostas e descamações. com melhora do estado geral, melhora discreta das lesões cutâneas em membros superiores, inferiores e face. Os sintomas neurológicos estabilizaram e atualmente o paciente apresenta-se paraparético com melhora da marcha. Após esse período foi suspensa a hidroxicloroquina e iniciado tratamento com talidomida na dose de $100 \mathrm{mg} /$ dia e redução gradativa da corticoterapia, com remissão das lesões cutâneas nos membros inferiores e superiores, mas persistência moderada na face. Houve redução da alopecia (Figura 1E).
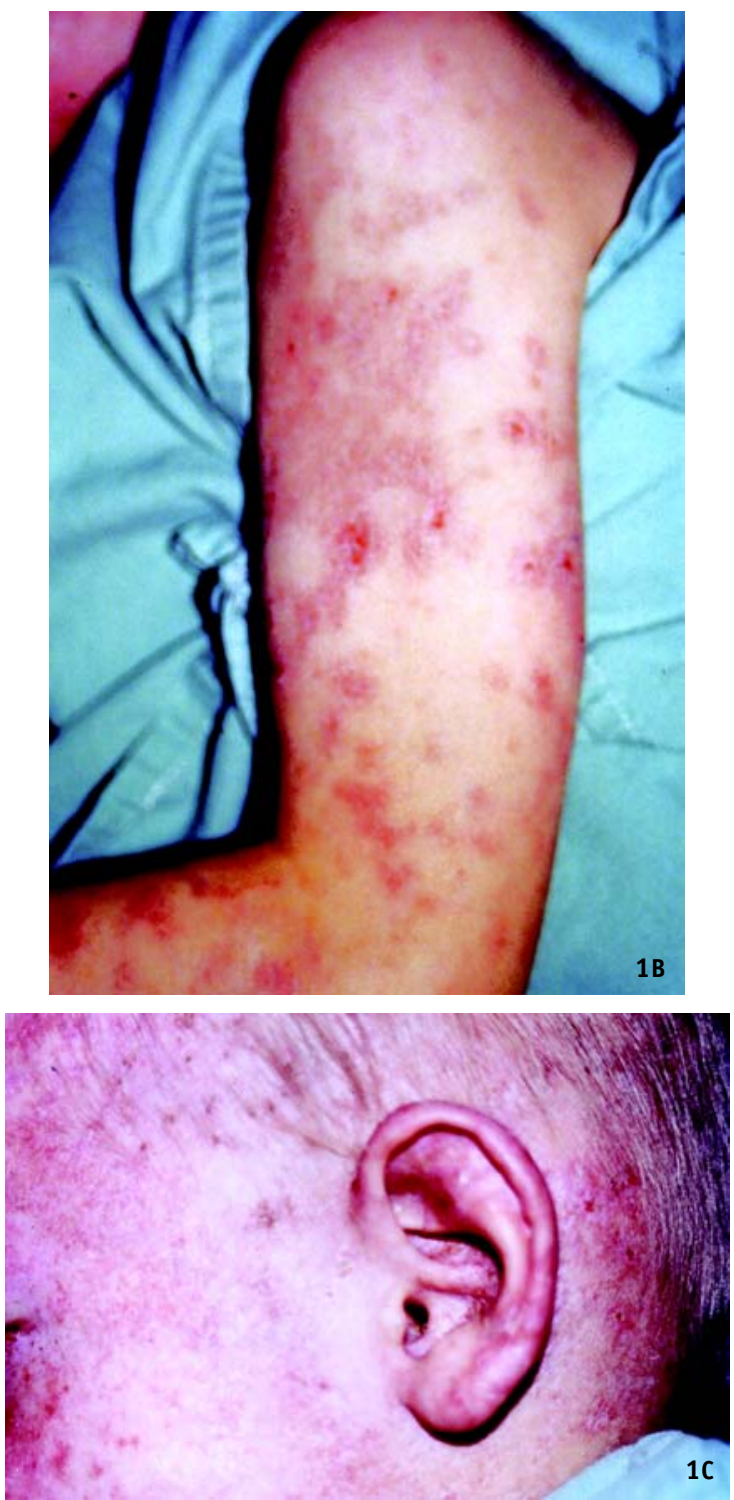

Figura $1 \mathrm{~B}$ e $1 \mathrm{C}$ - Lesões eritêmato-descamativas na pele, sendo algumas purpúricas, no tronco, membros superiores e inferiores, orelhas e couro cabeludo, além de petéquias nas mãos e pés. 

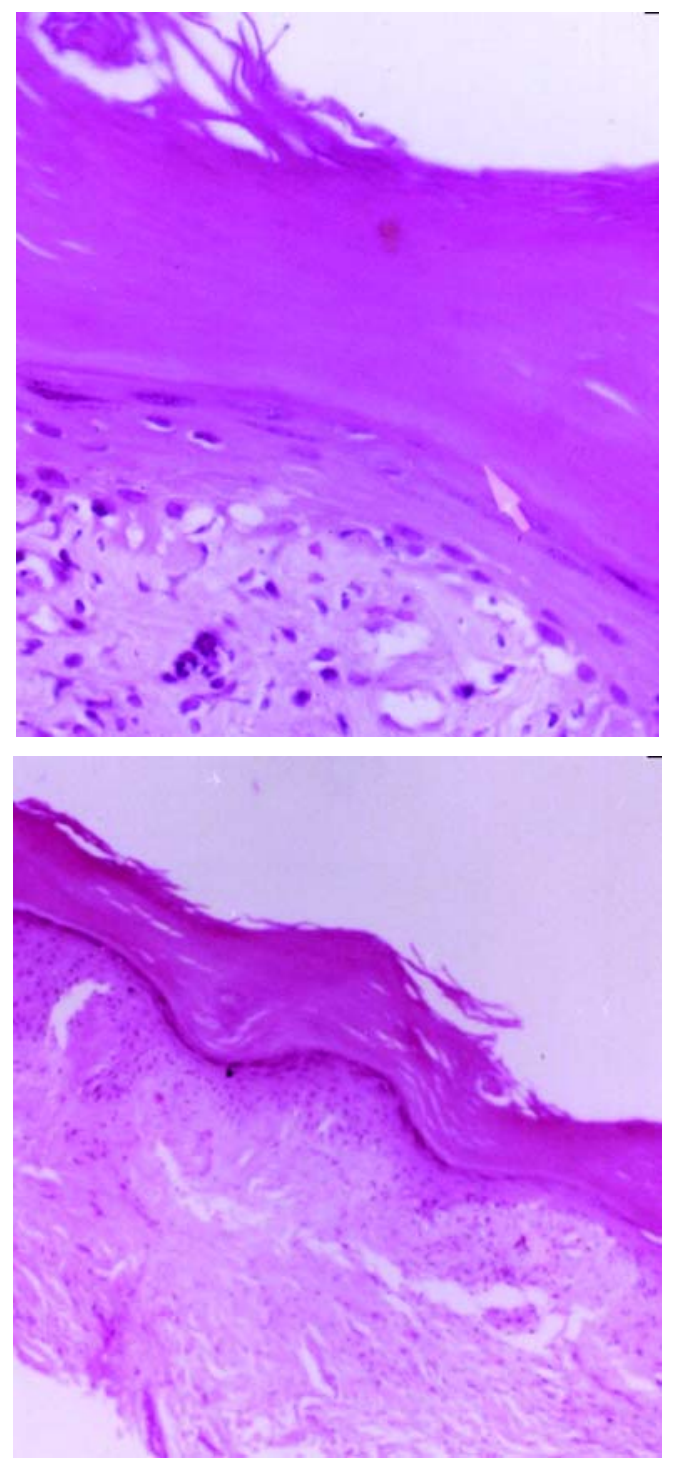

Figura $1 D$ - Biópsias de pele no antebraço direito. Epiderme COM hiperceratose, focos

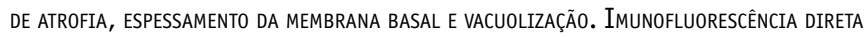

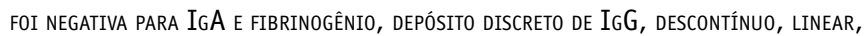
GRANULAR NA MEMBRANA BASAL; IGM E C3 COM DEPÓSITO INTENSO, LINEAR, GRANULAR NA MEMBRANA BASAL.

\section{RELATO DE CASO 2}

CCS, lactente, um mês, sexo masculino, com história de lesões eritematosas ovalares, desde o nascimento, na região de face, couro cabeludo, membros superiores, tronco e dorso. Foi atendido no pronto-socorro do Hospital Escola de Uberaba, com história de que há três dias havia iniciado com indisposição geral, febre e piora das lesões cutâneas. Mãe com história de duas gestações, dois partos normais,

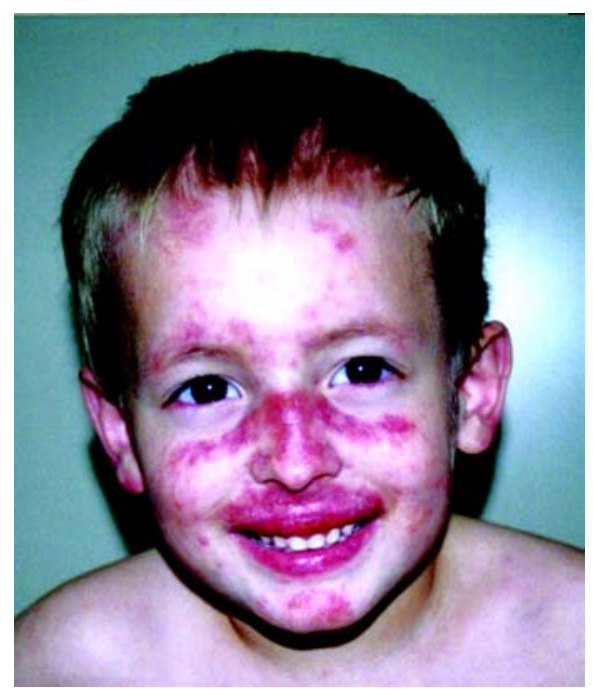

Figura 1E - Remissão das lesões cutâneas nos membros inferiores e superiores, persistindo moderadamente na face.

sem história de abortamentos, em acompanhamento no ambulatório de Reumatologia com diagnóstico de lúpus eritematoso cutâneo subagudo (LECS). Diagnóstico feito por apresentar lesões eritemato descamativas na face que apareceram durante a primeira gestação e desapareceram posteriormente sem deixar qualquer cicatriz. Além disso, apresentava FAN positivo 1:640 (padrão pontilhado), anti $\mathrm{SSb} / \mathrm{La}$ 1: 12.800 e anti SSa/Ro 1: 25.600. Irmão com história de poucas lesões de pele ao nascimento na face e no tronco que desapareceram em poucos meses. Antecedentes pessoais: nasceu de parto cesárea, com 3.500 gramas, gestação sem intercorrências. Ao exame apresentava: peso de $3.845 \mathrm{~g}$, estado geral regular, mucosas hipocoradas e hidratadas, acianótico, anictérico, temperatura axilar de $39^{\circ} \mathrm{C}$. Aparelho cardiopulmonar e abdome sem alterações. Lesões maculopapulares eritematosas, circinadas, algumas com leve atrofia central, na face, tronco, membros superiores e couro cabeludo (Figuras 2A e 2B). Exames laboratoriais: hemoglobina de 7,6g/dl; hematócrito de 20,7\%; hemácias 2,17 milhões $/ \mathrm{mm}^{3}$, plaquetas $65.000 / \mathrm{mm}^{3}$, leucócitos $5400 / \mathrm{mm}^{3}$ com diferencial de $3 \%$ de bastonetes, $37 \%$ de segmentados, $55 \%$ de linfócitos, $5 \%$ de monócitos; AST 102U/L, ALT 46U/L; Coombs direto e anti SSA/Ro negativos. Eletrocardiograma (ECG) com taquicardia sinusal, freqüência de $150 \mathrm{spm}$, padrão de sobrecarga ventricular direita. Ecodopplercardiograma evidencia pequeno canal arterial pérvio. Biópsia de pele revela epiderme com alteração vacuolar da camada basal, derme com depósito de 
mucina e extravasamento de hemáceas (compatível com lúpus neonatal). Baseados nos achados clínicos, laboratoriais, antecedentes familiares e exame histopatológico foi feito diagnóstico de lúpus neonatal. A febre regrediu para níveis de aferição normal em dois dias; as lesões de pele persistiram. Foi acompanhado ambulatorialmente e apresentou remissão das lesões em aproximadamente um mês.

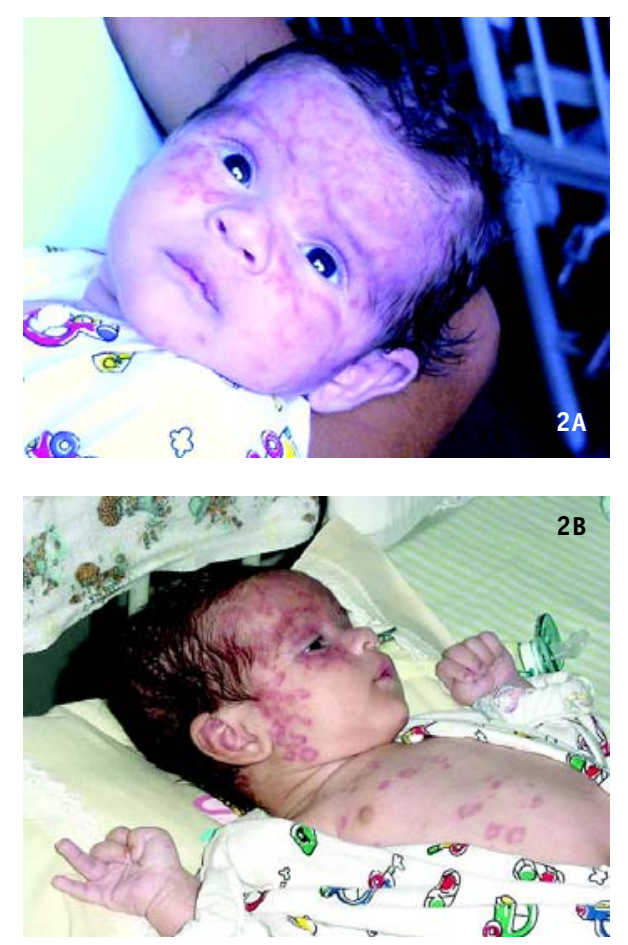

Figura 2A e 2B - Lesões maculopapulares eritematosas, circinadas, algumas com leve atrofia central, em face $(A)$, tronco, membros superiores e couro cabeludo (B).

\section{DISCUSSÃO}

O grupo de pacientes portadores de lúpus cutâneo parece não ser homogêneo e os critérios do ACR (American College of Reumatology) ${ }^{(6)}$ são de valor limitado para determinar a evolução dessa patologia ${ }^{(1)}$. Após um determinado período, de $50 \%$ a $60 \%$ dos pacientes com LC podem apresentar envolvimento sistêmico ${ }^{(7)}$. Isso foi relatado no caso clínico um, em que o paciente desenvolveu manifestação neurológica compatível com lesão piramidal.

Existem alguns indicativos, presentes no lúpus cutâneo, que podem predizer evolução para sistematização da doença: artralgia, sinais de nefropatia, FAN em altos títulos $>1: 320^{(1)}$.
O lúpus eritematoso cutâneo é raro em crianças, a incidência no período pré puberal não foi estabelecida, mas a incidência do LES tem sido estimada em 0,6/100000/ano e destes $18 \%$ ocorrem na infância ${ }^{(4)}$. O LECS tem sido associado freqüentemente com deficiência de complemento. A literatura relata deficiência de $\mathrm{C} 2$ ou $\mathrm{C} 4{ }^{(4)}$, a qual não foi observada no paciente deste estudo.

O caso um refere-se a paciente com LECS e alterações neurológicas no decorrer da fase aguda, sem outras patologias detectadas. O envolvimento do sistema nervoso central não é descrito no lúpus cutâneo, no entanto é encontrado como manifestação do $\operatorname{LES}^{(8)}$.

O lúpus cutâneo pode apresentar como complicação nefropatia, miocardite e vasculite do $\mathrm{SNC}^{(10)}$. O paciente descrito possui FAN positivo em altos títulos, o que favorece uma evolução para sistematização da doença ${ }^{(1)}$. Além deste marcador, o acometimento neurológico da criança constitui uma alteração sistêmica no sistema nervoso. Esses indicadores ficam como alerta para monitorização contínua e mais rigorosa da evolução da doença.

No lúpus neonatal as lesões podem ser exacerbadas e/ou induzidas pela exposição solar que não é pré-requisito para o aparecimento dessas lesões ${ }^{(5)}$, como ocorrido com o paciente do caso dois, que apresentou as lesões ao nascimento.

A histopatologia das lesões cutâneas do LN é semelhante à do LES. As lesões apareceram isoladamente em 72\% dos 60 casos japoneses publicados em 1992.

A trombocitopenia pode, ocasionalmente, ser severa. Entretanto, a hepatopatia e a trombocitopenia são transitórias, e apareceram, respectivamente, em apenas 10 e 4 dos 60 pacientes japoneses ${ }^{(10)}$. No caso dois foram observadas lesões cutâneas típicas e trombocitopenia. Das manifestações clínicas, as mais comumente relatadas são as lesões cutâneas e o bloqueio cardíaco total ${ }^{(5)}$, esse não evidenciado em nosso paciente. Porém, existe relato de outros comprometimentos cardíacos, como persistência do ducto arterioso $^{(10)}$, o qual se evidenciou no exame de ecodopplercardiograma do paciente que estudamos.

O diagnóstico laboratorial é realizado pela presença dos anticorpos anti Ro no soro da mãe ${ }^{(4)}$, que deve ser acompanhada durante a gestação para identificar o comprometimento cardíaco da criança. Segundo a literatura, esse comprometimento é em torno de $15 \%$ e, segundo o estudo de Saleeb et al. ${ }^{(11)}$, o tratamento com dexametasona oral pode diminuir ou reverter várias complicações do bloqueio cardíaco congênito.

A dermatose pelo anticorpo anti-Ro (observado no LES, LN e LECS) é causada pela citotoxicidade celular depen- 
dente do anticorpo anti Ro na epiderme e a lesão endotelial, na derme, pelos complexos imunes circulantes, anticorpo anti-DNA e anticorpo antiendotélio ${ }^{(5)}$. No paciente discutido, a ausência do anticorpo anti-Ro pode ser explicada pelo fato de a amostra sangüínea ter sido colhida aproximadamente um mês após nascimento da criança, quando já havia desaparecido da circulação sangüínea, o que normalmente ocorre com até seis meses de evolução.

\section{REFERÊNCIAS}

1. Tebbe B, Mansmann U, Wollina $U$, et al: Markers in cutaneous lúpus erythematosus indicating sistemic involviment. A multicenter study on 296 patients. Acta Derm Venereol (Stockh) 77: 305-8, 1997.

2. Buckley D, Barnes L: Childhood subcutaneous lúpus erythematosus associated with homozigous complement 2 deficiency. Pediatric Dermatol 12: 327-30, 1995.

3. Sontheimer RD, Thomas JR, Gilliam JN: Subacute cutaneous lúpus erythematosus. A cutaneous marker for a distintc lúpus erythematosus subset. Arch Dermatol 115: 1409-15, 1979.

4. Lee LA, Weston WL: Cutaneous lúpus erythematosus during the neonatal and childhood periods. Lúpus 6: 132-8, 1997.

5. Furukawa F, Hiroi A: Collagen diseases in children. Clinics in Dermatol 18: 725-33, 2000.

6. Tan EM, Cohen AS, Fries JF, et al: The 1982 revised criteria for the classification of systemic lupus erythematosus. Arthritis Rheum 25: 1271-7, 1982.
Concluímos, com a apresentação desses casos de lúpus cutâneo na criança, que, apesar da raridade, devemos estar atentos para o diagnóstico precoce e melhor abordagem terapêutica. Particularmente nos casos de mães portadoras do anticorpo anti-Ro, para detecção e até possível reversão das complicações do bloqueio cardíaco congênito na criança, e nas próximas gestações ${ }^{(12)}$.

7. Callen JP, Klein J: Subacute cutaneous lúpus erythematosus. Clinical, serologic, imunogenetic, and therapeutic consideration in seventytwo patients. Arthrits Rheum 31: 1007-13, 1998.

8. Schmutzler KMRS, Vilanova LCP, Lima JGC, Hilário MO, Naspitz CK: Juvenile systemic lúpus erythematosus. Arc Neuropsiquiatr 57: 606-9, 1992.

9. Hernández D, Lanza A, Vargas-Arenas RE: Lúpus Eritematoso Cutaneo Subagudo. Estudio retrospectivo. Arch Hosp Vargas 29: 41-5, 1987.

10. Kaneko F, Taniji $\mathrm{O}$, Hasegawa T, et al: Neonatal lúpus erythematosus in Japan. J Am Acad Dermatol 26: 397-403, 1992.

11. Saleeb S, Copel J, Friedman D, Buyon JP: Comparison of treatment with fluorinated glucocorticoids to natural history of autoantibodyassociated congenital heart block: retrospective review of the Research Registry for Neonatal Lupus. Arthritis Rheum 42: 2335-45, 1999.

12. Neiman AR, Lee LA, Weston WL, Buyon JP: Cutaneous manifestations of neonatal lúpus without heart block: characteristics of mothers and children in a national regystry. J Pediatr 137: 674-80, 2000. 